\title{
Cadmium Assisted Photochemical Vapor Generation of Tungsten for Detection by Inductively Coupled Plasma Mass Spectrometry
}

Jaromír Vyhnanovský, ${ }^{\dagger \dagger}$ Ralph E. Sturgeon, ${ }^{\S}$ and Stanislav Musil* ${ }^{* \dagger}$

†Institute of Analytical Chemistry of the Czech Academy of Sciences, Veveř́ 97, 60200 Brno, Czech Republic

Charles University, Faculty of Science, Department of Analytical Chemistry, Albertov 8, 128 43 Prague, Czech Republic

${ }^{\S}$ National Research Council of Canada, 1200 Montreal Road, Ottawa, Ontario K1A 0R6, Canada

* Corresponding author; E-mail: stanomusil@biomed.cas.cz (S. Musil)

\begin{abstract}
This supplementary material details a PVG system coupled to ICPMS; ICPMS parameters used for PVG (Table S1); CRM CTA-FFA-1 and water sample preparation procedures; PVG transient signals obtained from $10 \%$ formic acid without added $\mathrm{Cd}^{2+}$ (Figure S1); effect of reaction medium/sample flow rate through the photoreactor (Figure S2); effect of other added transition metals ions $\left(\mathrm{Fe}^{2+}, \mathrm{Cu}^{2+}\right.$ and $\left.\mathrm{Co}^{2+}\right)$ on $\mathrm{PVG}$ in a $40 \%$ formic acid medium (Figure $\mathrm{S} 3$ ); relative effects of added inorganic compounds on PVG of W (Figure S4); characteristics of the recorded FI peak profile and its broadening; exploration of PVG mechanism including UV-vis absorption spectra of reaction media (Figure S5).
\end{abstract}




\section{EXPERIMENTAL SECTION}

\section{Instrumentation}

Sample solutions were introduced in a flow-injection (FI) mode into a stream of the reaction medium with the aid of an injection valve ( $470 \mu \mathrm{L}$ precise sample volume). Unless otherwise stated, it was delivered at a flow rate of $2 \mathrm{~mL} \mathrm{~min}^{-1}$ to the photoreactor using a peristaltic pump (Reglo Digital, Ismatec) which was also used to evacuate waste from the gas-liquid separator (GLS). All connecting tubing was made of PTFE (i.d. $1 \mathrm{~mm}$ ) with the exception of the Tygon pump tubing. The high-efficiency flow-through photoreactor comprised a $19 \mathrm{~W}$ low-pressure mercury discharge lamp (Beijing Titan Instruments Co., Beijing, China) having a synthetic quartz central channel of $\approx 720 \mu \mathrm{L}$ internal volume. The effluent was mixed with a flow of argon (Ar chemifold) and directed to a GLS (15 mL internal volume) which, unless otherwise stated, was made from a polypropylene (PP) centrifuge vial fitted with a PTFE lid. This lid contained three sealed ports which permitted access for tubing for liquid sample delivery and waste removal as well as gas outlet. The tip of the PTFE waste tube was terminated $2.5 \mathrm{~cm}$ from the bottom of the GLS unit in order to maintain a stable liquid level inside the unit $(\approx 2 \mathrm{~mL})$. The separator was almost completely immersed in an ice-water bath to minimize any liquid carryover. Unless otherwise stated, the outlet of the GLS was connected via PTFE tubing (2 $\mathrm{mm}$ i.d. x $62 \mathrm{~cm}$ long) to the inlet of a Scott-type spray chamber (normally the inlet for makeup Ar), thereby serving to transfer the volatile tungsten species directly to the ICP torch.

Carrier liquid ( $2 \% \mathrm{HNO}_{3}$ or DIW), mixed with an internal standard (IS) comprising $10 \mu \mathrm{g} \mathrm{L}^{-1}$ $\mathrm{Rh}$ in $2 \% \mathrm{HNO}_{3}$, was nebulized into the spray chamber of the ICPMS using a MicroMist nebulizer concurrently with PVG sample introduction in order to simultaneously provide more robust "wet plasma" conditions and to monitor plasma stability. The channel for carrier liquid was equipped with a manual injection valve $(260 \mu \mathrm{L})$ that was utilized exclusively for determination of the overall PVG efficiency by comparing sensitivities obtained with PVG sample introduction and conventional solution nebulization.

An Agilent 7700x single quadrupole ICPMS was used as a detector. Optimal plasma settings are summarized in Table $\mathrm{S} 1$. 
Table S1. Typical ICPMS Parameters for Coupling with PVG.

\begin{tabular}{cc}
\hline RF power & $1600 \mathrm{~W}$ \\
Nebulizer Ar & $1.05 \mathrm{~L} \mathrm{~min}^{-1}$ \\
Dilution Ar & $0.0 \mathrm{~L} \mathrm{~min}^{-1}$ \\
Ar(chemifold) for PVG & $100 \mathrm{~mL} \mathrm{~min}^{-1}$ \\
ICPMS sample flow & $0.32 \mathrm{~mL} \mathrm{~min}^{-1}$ carrier liquid, $0.07 \mathrm{~mL} \mathrm{~min}^{-1} \mathrm{IS}$ \\
ICPMS spray chamber & $2{ }^{\circ} \mathrm{C}$ \\
temperature & no gas \\
Reaction/collision cell mode \\
Measurement mode \\
time resolved analysis \\
Measured isotopes (dwell time, s)
\end{tabular}

Isotopes of ${ }^{103} \mathrm{Rh}$ (dwell time $\left.0.05 \mathrm{~s}\right),{ }^{182} \mathrm{~W}(0.1 \mathrm{~s})$ and ${ }^{184} \mathrm{~W}(0.1 \mathrm{~s})$ were typically recorded. If necessary, ${ }^{111} \mathrm{Cd}$ was also monitored $(0.05 \mathrm{~s})$. Measurements were performed in time resolved analysis mode with no gas in the reaction/collision cell. All results are presented using ${ }^{182} \mathrm{~W}$ signal intensity for evaluation; no statistically significant difference was evident when ${ }^{184} \mathrm{~W}$ was used for evaluation. A standard tuning procedure was conducted daily to check the sensitivity of the instrument. This was followed by further tuning while operating in PVG mode. The optimum nebulizer Ar flow rate was manually tuned daily. The FI signals were exported to, and integrated with, MS Excel and corrected for any sensitivity drift relative to changes in the ${ }^{103} \mathrm{Rh}$ IS signal intensity.

\section{Sample Preparation}

An accurately known mass of approximately $0.15 \mathrm{~g}$ of the Certified Reference Material (CRM) CTA-FFA-1 (Fine Fly Ash) was weighed into a $15 \mathrm{~mL} \mathrm{PP} \mathrm{vial} \mathrm{and} 2 \mathrm{~mL} \mathrm{HNO}_{3}, 1 \mathrm{~mL} \mathrm{HCl}$ and $0.5 \mathrm{~mL}$ HF were added. The sample and a corresponding blank were prepared in triplicate. The vials were placed into a hot block set to $125^{\circ} \mathrm{C}$. To decrease the amount of residual inorganic acids (mainly HF), the sample was left to evaporate to a final volume of approximately $2 \mathrm{~mL}$. The total time for digestion and evaporation was 4 hours. Digests were diluted to $50 \mathrm{~mL}$ with DIW. Prior to their analysis by FI-PVG-ICPMS, sample test aliquots were further diluted 200fold with the carrier solution containing $500 \mathrm{mg} \mathrm{L}^{-1} \mathrm{Cd}^{2+}$ as a sensitizer. A corresponding 
parallel determination using conventional solution nebulization ICPMS as a reference methodology necessitated the sample being diluted 100 -fold with $2 \% \mathrm{HNO}_{3}$.

Six water samples were employed to demonstrate a practical feasibility of the developed methodology. The samples included a tap water collected in the laboratory, a river water collected from the Vltava river in Prague, two groundwater samples collected from the wells in a district of Prague (marked as groundwater I and II) and two groundwater samples collected near a chemical factory in the city of Břeclav, Czech Republic (groundwater III and IV). The water samples were filtered through a $0.45 \mu \mathrm{m}$ PTFE filter and prepared for parallel analysis with conventional solution nebulization ICPMS (prepared in $2 \% \mathrm{HNO}_{3}$ ) or with FI-PVGICPMS (prepared in $40 \%$ formic acid containing $500 \mathrm{mg} \mathrm{L}^{-1} \mathrm{Cd}^{2+}$ ). Groundwater samples III and IV with higher W content were diluted with DIW (1:1) before analysis by both approaches.

\section{RESULTS AND DISCUSSION}

\section{Initial PVG Assessment}

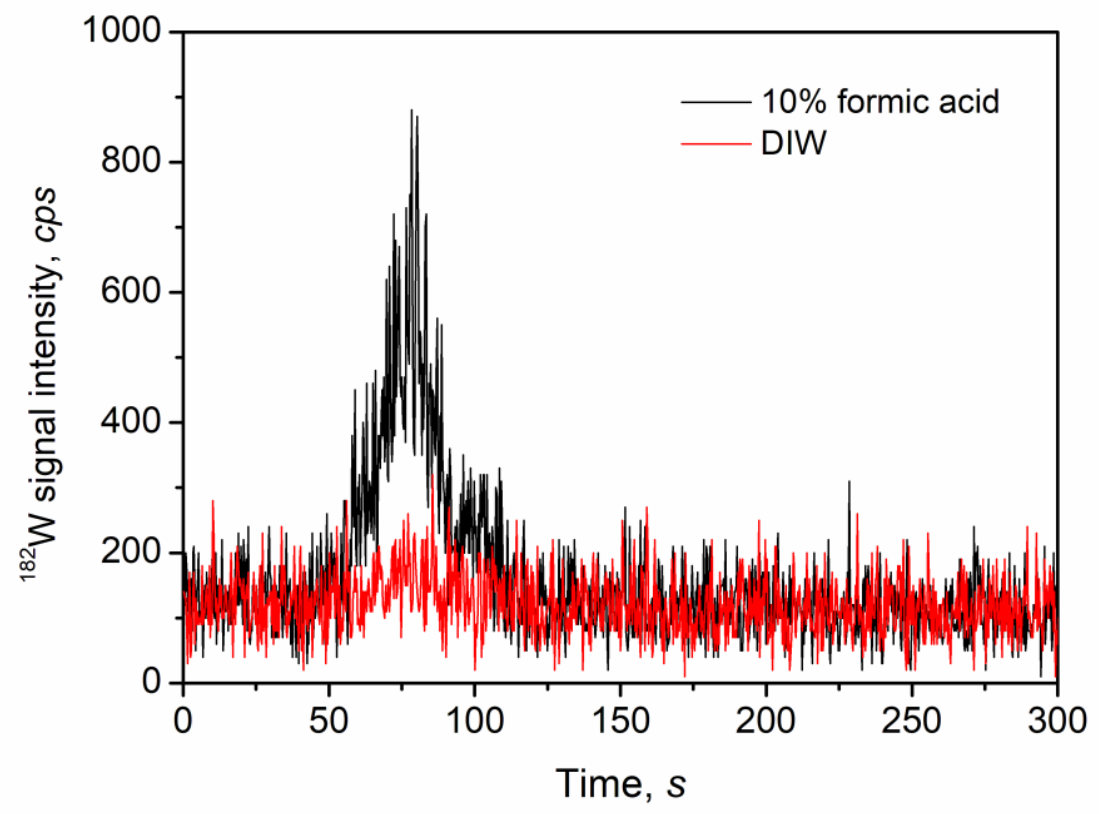

Figure S1. PVG transient signals of ${ }^{182} \mathrm{~W}$ from $10 \mu \mathrm{g} L^{-1} \mathrm{~W}$ generated from $10 \%(\mathrm{v} / \mathrm{v})$ formic acid (black line) and from DIW (red line) by FI-PVG-ICPMS. 


\section{PVG Conditions}

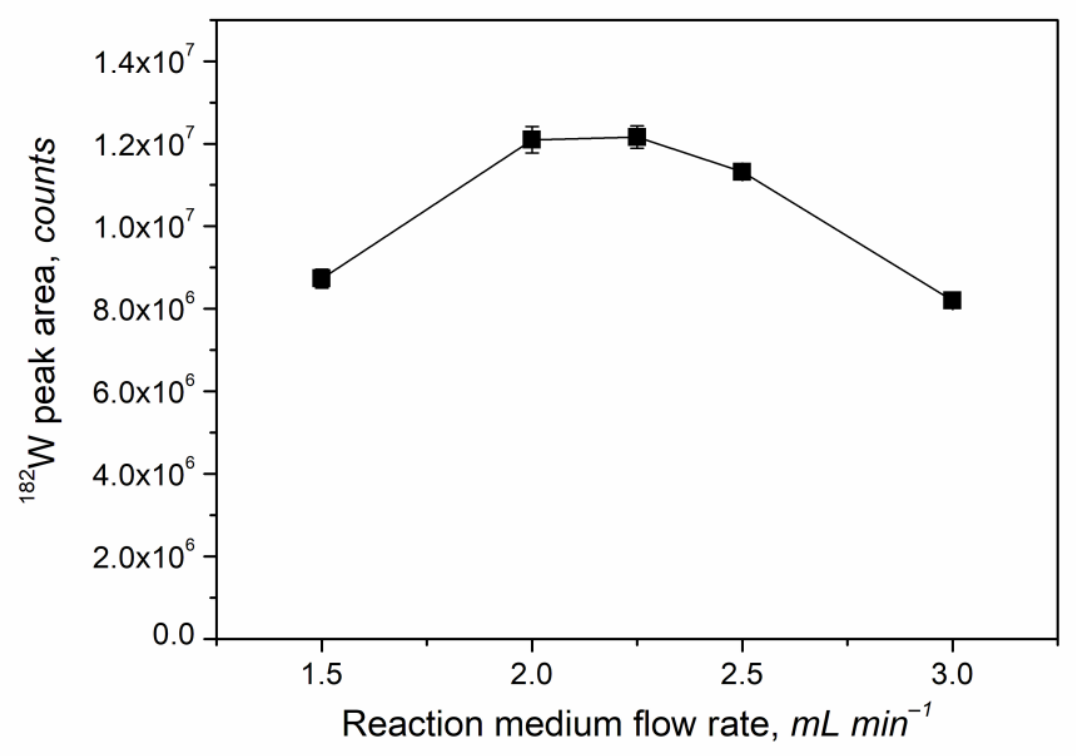

Figure S2. Effect of reaction medium/sample flow rate $140 \%$ formic acid reaction medium, $100 \mathrm{mg} \mathrm{L}^{-1} \mathrm{Cd}^{2+}$ as a sensitizer) on peak area response from $0.5 \mu \mathrm{g} \mathrm{L}^{-1} \mathrm{~W}$. Uncertainties expressed as $S D$.

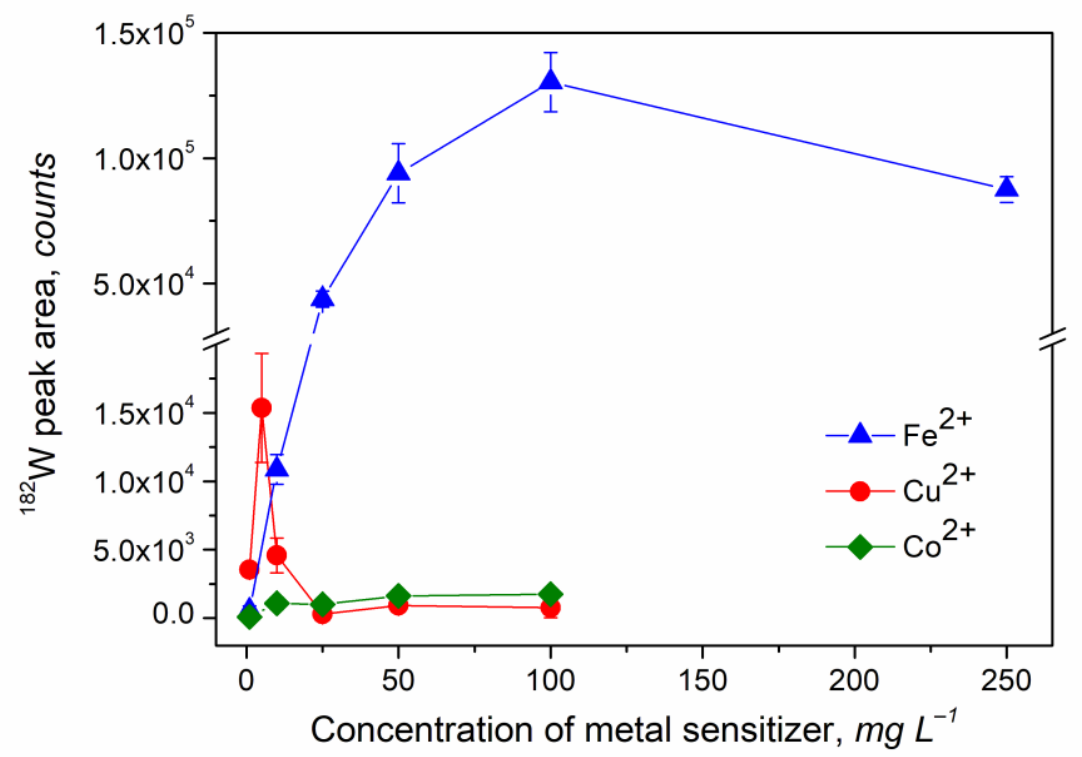

Figure S3. Effect of added $\mathrm{Fe}^{2+}, \mathrm{Cu}^{2+}$ and $\mathrm{Co}^{2+}$ on $\mathrm{PVG}$ response from $0.5 \mu \mathrm{g} \mathrm{L}^{-1} \mathrm{~W}$ in $40 \%$ formic acid. Uncertainties expressed as $S D$. 


\section{Interferences}

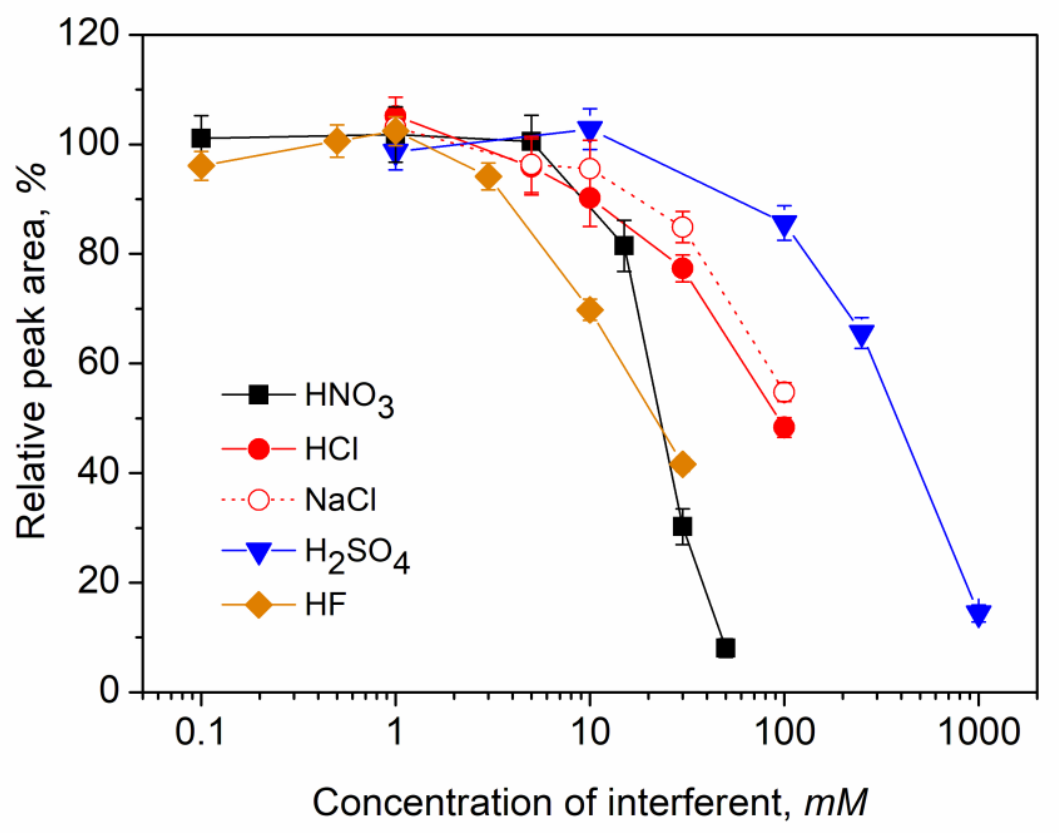

Figure S4. Relative effects of added inorganic compounds on PVG of $0.5 \mu g L^{-1} W$ in $40 \%$ formic acid containing $500 \mathrm{mg} \mathrm{L}^{-1}$ Cd as a sensitizer. Uncertainties expressed as combined SD.

\section{Figures of Merit}

It is evident from the transients presented in Figure 2 that the FI signals for W suffer from tailing. The time necessary for the baseline to return to $5 \%$ and $1 \%$ of the peak after sample injection is as long as $125 \mathrm{~s}$ and $180 \mathrm{~s}$, respectively. For comparison, the ${ }^{111} \mathrm{Cd}$ signal returns fully to baseline in $125 \mathrm{~s}$. Analyte delay in the photoreactor and dead volumes of the GLS $(13 \mathrm{~mL})$ and spray chamber of the ICPMS $(65 \mathrm{~mL})$ likely accounts for this tailing. Taking into account the flow rates through the GLS (100 $\mathrm{mL} \mathrm{min}^{-1} \mathrm{Ar}$ chemifold used) and the spray chamber (1.15 $\mathrm{L} \mathrm{min}^{-1}$ total Ar flow), the minimum residence time of the gaseous analyte in the dead volumes is approximately $11 \mathrm{~s}$. The gas does not flow as a plug and gaseous analyte is continuously diluted by the fresh transport gases. Hence, it can be assumed that it takes at least 5 half-lives to completely wash-out the gaseous analyte. Accounting for this, the above transport time, when multiplied by 5 , increases to $55 \mathrm{~s}$. If this effective wash-out time is added to the time at peak maximum of $71 \mathrm{~s}, 126 \mathrm{~s}$ is obtained, accounting for the greater part of the full signal width, especially when it is recognized that the peak time does not correspond to the 
end of the analyte introduction process into the GLS and spray chamber. In an attempt to further identify the origin of the long wash-out time for tungsten, additional experiments were conducted. Both the peristaltic pumps were stopped and the photoreactor was switched off at time corresponding to $120 \mathrm{~s}$. Absolutely no change in the decline to baseline was observed, suggesting the long "wash-out" does not arise from any adsorption/desorption effects in the photoreactor. This is supported by the fact that a zone of $\mathrm{Cd}$ is definitely no longer present in the photoreactor after $120 \mathrm{~s}$ and PVG of W should not proceed further. Therefore, the extended signal duration must be associated with the generated volatile species and takes place in the apparatus downstream of the photoreactor, i.e., connecting tubing, the GLS, spray chamber and/or the torch. The GLS is typically immersed in an ice bath to support condensation of formic acid vapors and liquid droplets and to limit their transfer to the plasma. Attempts to heat the GLS in a thermoblock to $65^{\circ} \mathrm{C}$ or $80^{\circ} \mathrm{C}$ in an effort to reduce the solubility of the gaseous $\mathrm{W}$ species did not shorten the wash-out period. Peak area response was also not improved as 104 $\pm 6 \%$ and $108 \pm 5 \%$ relative responses were achieved. Changing the material of the GLS from plastic to glass also did not improve the situation.

\section{Exploration of PVG Mechanism}

Tungsten species are present in the environment in several oxidation states but the VI state is dominant. Tungstate species are stable in alkaline solutions and at $\mathrm{pH}<7$ precipitation of tungstic acid $\left(\mathrm{H}_{2} \mathrm{WO}_{4}\right.$ or $\left.\mathrm{WO}_{3} \cdot \mathrm{H}_{2} \mathrm{O}\right)$ occurs at high concentrations of $\mathrm{WO}_{4}{ }^{2-}$. In dilute acidic solutions at $\mathrm{pH} \approx 1$ (equivalent to $40 \%$ formic acid) precipitation should not occur. ${ }^{1}$

It is assumed that the volatile species generated by PVG is $\mathrm{W}(\mathrm{CO})_{6}$ (b.p. of $175^{\circ} \mathrm{C}$ ), based on the reaction medium used (formic acid) that can give rise to only carbonylated adducts. This, however, remains to be conclusively proven by GC-MS. This stable species, fulfilling the 18 electron rule, has been identified in gaseous effluents from landfill and sewage sites. ${ }^{2,3}$ If this is indeed the only product, the mechanism of PVG would include reduction of W(VI) to $\mathrm{W}(0)$ followed by rapid uptake of CO, readily available as a product of photolysis of formic acid.

Papaconstantinou ${ }^{4}$ spectrophotometrically followed the 1-, 2-, 4-, and 6-electron step-wise reduction of the isopoly- as well as the heteropoly-species Mo(VI) and $\mathrm{W}(\mathrm{VI})$ by organic free radicals derived from $\gamma$-radiolysis of solutions of simple alcohols and formic acid. On this basis, the reduction potential of the (protonated) carboxyl anion radical at $\mathrm{pH} \approx 1\left(\mathrm{pK}_{\mathrm{a}}=1.6\right)$ was estimated to be $<-0.89 \mathrm{~V}$ (vs SHE) as it was capable of undertaking complete 6-electron 
reduction of all of the Mo species whose redox potentials are all more positive than this, but only 4- electron reduction of the corresponding tungstate species. Furthermore, it was proposed that at $\mathrm{pH} \approx 4$ the reducing ability of $\mathrm{CO}_{2}{ }^{--}$radicals should be stronger and capable of the full 6- electron reduction of tungstate. This statement was also recently mentioned by Leonori and Sturgeon ${ }^{5}$ who suggested an increase of $\mathrm{pH}$ to 4 as a possible means of achieving successful PVG of W. However, as evident from this work, despite use of a higher $\mathrm{pH}$ for the reaction medium (10\% and $40 \%$ formic acid with addition of various formate concentrations) without $\mathrm{Cd}^{2+}$ ions, efficient PVG of $\mathrm{W}$ remained elusive. In the presence of $\mathrm{Cd}^{2+}$ sensitizer, such an increase in the $\mathrm{pH}$ of the reaction medium actually appears detrimental, as PVG efficiency is impaired, pointing to a possibly different reduction mechanism in the presence of $\mathrm{Cd}^{2+}$ ions.

In order to investigate the influence of absorbed UV wavelength on feasibility of PVG of W, a commonly used low-pressure $15 \mathrm{~W}$ germicidal mercury UV lamp (Cole-Parmer) was used with which a sample solution was irradiated while flowing in a $6 \mathrm{~m}$ length of $1 \mathrm{~mm}$ i.d. $x 1.5 \mathrm{~mm}$ o.d. PTFE tubing wrapped around the lamp. This experimental arrangement was earlier used by Guo et al. for efficient generation of Ni tetracarbonyl. ${ }^{6}$ However, no or negligible efficiency was achieved with this arrangement for PVG of Mo. ${ }^{7}$ In comparison to the high-efficiency flowthrough photoreactor, this arrangement does not permit irradiation of the solution with $185 \mathrm{~nm}$ line. Without optimization of PVG parameters, PVG of $\mathrm{W}$ was found feasible with the germicidal lamp when optimal conditions for the high-efficiency flow-through photoreactor were used. The relative response was approximately $4 \%$ and $12 \%$ of that typically achieved with the high-efficiency flow-through photoreactor for $40 \%$ formic acid in the presence of 100 and $500 \mathrm{mg} \mathrm{L}^{-1} \mathrm{Cd}^{2+}$, respectively. These values reflect an overall absolute PVG efficiency of approximately $1.0 \%$ and $5.4 \%$. This is evidence that $185 \mathrm{~nm}$ radiation is not essential for PVG of $\mathrm{W}$ when $\mathrm{Cd}^{2+}$ is used as the sensitizer, as opposed to the case of PVG of Mo. ${ }^{7}$

The effect of the presence of transition metal ions in the reaction medium on PVG efficiency has often been associated with formation of metal formate complexes which change the absorption characteristics of the reaction medium. Such a change may enhance the rate of photo-oxidation of formic acid ${ }^{8,9}$ and/or alter the reaction scheme in favor of production of highly reducing radicals such as the aquated electron, $\mathrm{HCO}_{2}{ }^{-}$as well as $\mathrm{CO}_{2}^{--}$radicals responsible for reduction. ${ }^{10} \mathrm{UV}$-vis absorption spectra of various reaction media (40\% formic acid without and with the addition of $\mathrm{Cd}^{2+}$ and with various concentrations of $\mathrm{W}$ ) referenced to DIW are displayed in Figure S5. 


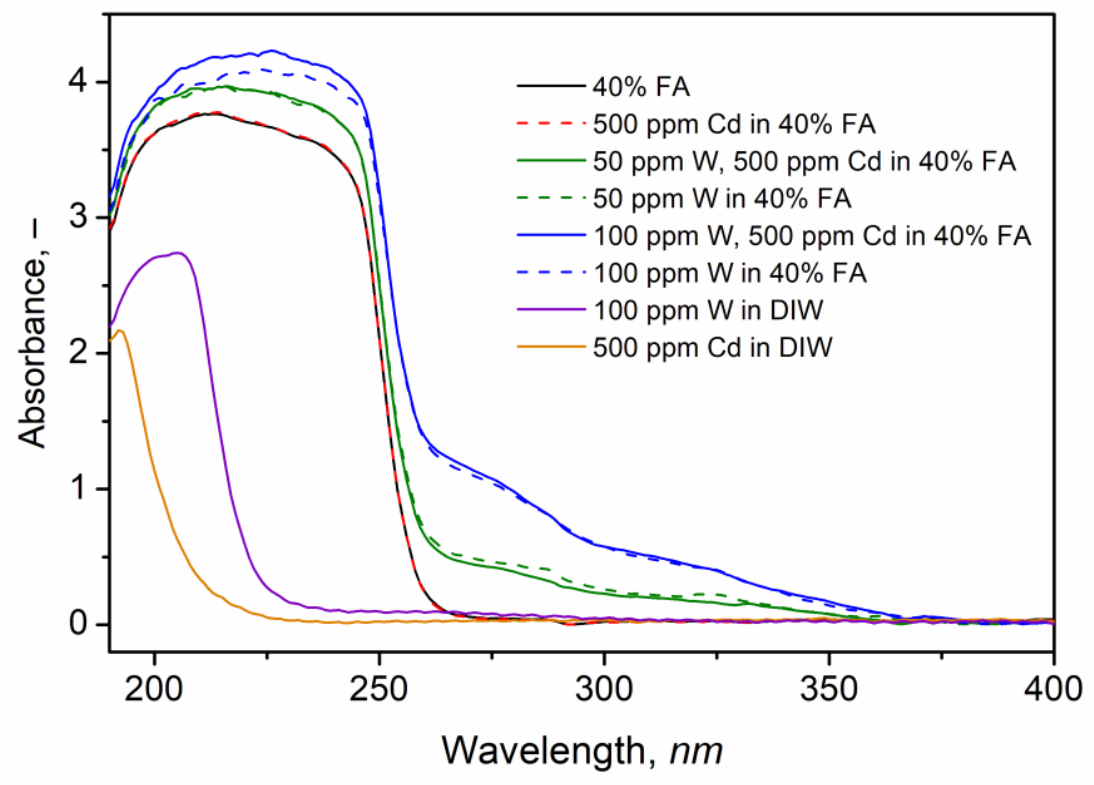

Figure S5. UV-vis absorption spectra of reaction media referenced against DIW with or without addition of $\mathrm{Cd}^{2+}$ and with various concentrations of $W$.

As evident, significant absorption by formic acid occurs at wavelengths below $260 \mathrm{~nm}$. No absorption band can be ascribed to $\mathrm{Cd}^{2+}$ ions in $40 \%$ formic acid because the spectra obtained without and with $500 \mathrm{mg} \mathrm{L}^{-1} \mathrm{Cd}^{2+}$ appear identical. No change or shift in the spectra was identified when the reaction medium containing $500 \mathrm{mg} \mathrm{L}^{-1} \mathrm{Cd}^{2+}$ was irradiated by passage through the photoreactor. Hence, formation of any nanostructures of $\mathrm{Cd}$ species, such as has been reported for CdTe, CdSe and CdS in-situ generated particles, ${ }^{11}$ could not be confirmed. Addition of W(VI) to the reaction medium resulted in the appearance of a significant absorption band having a maximum at $255-260 \mathrm{~nm}$ (maximum determined from measurements relative to $40 \%$ formic acid) which increased with $\mathrm{W}$ concentrations but was not influenced by the presence of $\mathrm{Cd}^{2+}$. Since the absorption band attributed to $\mathrm{WO}_{4}{ }^{2-}$ in DIW occurs at lower wavelengths, formation of a tungsten formate complex likely occurs.

Unfortunately, beyond these simple diagnostics, a full mechanistic interpretation of the mechanism of PVG of $\mathrm{W}$ in the presence of $\mathrm{Cd}^{2+}$ cannot be advanced at this time. 


\section{REFERENCES}

1. Barré, T.; Arurault, L.; Sauvage, F. X. Chemical behavior of tungstate solutions: Part 1. A spectroscopic survey of the species involved. Spectrochim. Acta, Part A 2005, 61 (4), 551557.

2. Feldmann, J.; Cullen, W. R. Occurrence of Volatile Transition Metal Compounds in Landfill Gas: Synthesis of Molybdenum and Tungsten Carbonyls in the Environment. Environ. Sci. Technol. 1997, 31 (7), 2125-2129.

3. Feldmann, J. Determination of $\mathrm{Ni}(\mathrm{CO}) 4, \mathrm{Fe}(\mathrm{CO}) 5, \mathrm{Mo}(\mathrm{CO}) 6$, and $\mathrm{W}(\mathrm{CO}) 6$ in sewage gas by using cryotrapping gas chromatography inductively coupled plasma mass spectrometry. J. Environ. Monit. 1999, 1 (1), 33-37.

4. Papaconstantinou, E. New easy method for obtaining approximate redox potentials of radicals, produced by cobalt-60-.gamma.-radiolysis, using heteropoly electrolytes of molybdenum and tungsten as electron acceptors. Redox potential of some alcohol and organic acid radicals. Anal. Chem. 1975, 47 (9), 1592-1595.

5. Leonori, D.; Sturgeon, R. E. A unified approach to mechanistic aspects of photochemical vapor generation. J. Anal. At. Spectrom. 2019, 34 (4), 636-654.

6. Guo, X. M.; Sturgeon, R. E.; Mester, Z.; Gardner, G. UV photosynthesis of nickel carbonyl. Appl. Organomet. Chem. 2004, 18 (5), 205-211.

7. Šoukal, J.; Sturgeon, R. E.; Musil, S. Efficient Photochemical Vapor Generation of Molybdenum for ICPMS Detection. Anal. Chem. 2018, 90 (19), 11688-11695.

8. Sturgeon, R. E.; Grinberg, P. Some speculations on the mechanisms of photochemical vapor generation. J. Anal. At. Spectrom. 2012, 27 (2), 222-231.

9. Sturgeon, R. E. Photochemical vapor generation: a radical approach to analyte introduction for atomic spectrometry. J. Anal. At. Spectrom. 2017, 32 (12), 2319-2340.

10. Baxendale, J. H.; Bridge, N. K. Photoreduction of Ferric Compounds in Aqueous Solution. J. Phys. Chem. 1955, 59 (8), 783-788.

11. Xu, F. J.; Zou, Z. R.; He, J.; Li, M. T.; Xu, K. L.; Hou, X. D. In situ formation of nano$\mathrm{CdSe}$ as a photocatalyst: cadmium ion-enhanced photochemical vapour generation directly from Se(VI). Chem. Commun. 2018, 54 (38), 4874-4877. 